\title{
IN-VITRO MULTIPLICATION OF GINGER (Zingiber officinale ROSC.) CULTIVARS LOCAL, CHINESE AND RANGUN
}

\author{
${ }^{1 *}$ D.B.R. Swarnathilaka, ${ }^{2}$ N.S. Kottearachchi and ${ }^{2}$ W.J.S.K.Weerakkody \\ ${ }^{1}$ Plant Tissue Culture Research Station, Dept of Export Agriculture, Walpita, Sri Lanka \\ ${ }^{2}$ Department of Biotechnology, Faculty of Agriculture and Plantation Management, University of Wayamba, Sri \\ Lanka
}

\begin{abstract}
In Ginger, it is necessary to find an alternative method for production of disease free planting materials as the conventional propagation technique through rhizomes transmit many diseases. The present study summarizes an efficient micropropagation method developed for Zingiber officinale Rosc. (Ginger) cultivar, Local, Chinese and Rangun using sprouted bud explants from fresh rhizomes.

Newly sprouted rhizome buds with the size of $0.5-1.0 \mathrm{~cm}$ were surface sterilized with $30 \%$ Clorox for 30 minutes prior to culture and this treatment resulted $60 \%-70 \%$ healthy pure explants for all three cultivars. Murashige and Skoog (1962) medium has shown the best performance in culture establishment for three cultivars. Highest survival rate of the explants was observed in the cultivar, Chinese while lowest was observed in Local ginger. MS medium supplemented with $2 \mathrm{mgl}^{-1} \mathrm{BA}$ and $0.25 \mathrm{mg} \mathrm{l}^{-1}$ NAA was shown the best performance for initial multiplication of ginger buds (8.6 shoots per explants) in the cultivar, Local. However buds of Rangun and Chinese were shown the highest rate of multiplication (respectively 7.33 and 7.20 shoots per explants) in the MS supplemented with $4.0 \mathrm{mg} \mathrm{l}^{-1} \mathrm{BAP}$ and $0.25 \mathrm{mg} \mathrm{l}^{-1} \mathrm{NAA}$. Half strength of MS medium supplemented with $1.5-2.0 \mathrm{mg} \mathrm{l}^{-1} \mathrm{NAA}$ has shown induction of roots in ginger cultivars tested. Of the combination tested $1 / 2$ strength MS with $1.50 \mathrm{mg} \mathrm{l}^{-1}$ NAA elicited optimal rooting response in which an average of 5.5 roots with $3.64 \mathrm{~cm}$. root length for cultivar Local. But highest value of root length $4.95(\mathrm{~cm})$ and $4.12(\mathrm{~cm})$ were recorded in plantlets of Rangun and Chinese respectively in the half strength MS medium with $2.0 \mathrm{mgl}^{-1} \mathrm{NAA}$. Further experiments are being continued for acclimatization of in-vitro raised plants.
\end{abstract}

Keywords: Ginger, explants of sprouted buds, micropropagation, Zingiber officinale

\section{INTRODUCTION}

Ginger (Zingiber officinale Rosc.) is a well known oriental spice crop having significant commercial value for its use in various medicinal and culinary preparations. It is usually propagated through the underground rhizomes with a low multiplication rate. Several local and imported ginger cultivars namely Local, Rangun and Chinese are grown in Sri Lanka in large scale. Rhizomes of local ginger are small and the fibrous flesh is somewhat ash white in color. Its' taste and aroma are comparatively higher than Rangun and Chinese. It is largely used as a spice, a beverage and a basic material in pharmaceutical industry. Rhizomes of Chinese are large with watery flesh which is pale yellow in color. It is largely used for pickles because of the low taste and aroma. Rhizome of Rangun is medium in size and with well spread finger rhizomes and the taste and the aroma exists in between local and Chinese. In order to increase the production of ginger, high quality planting materials are required. As ginger is propagated exclusively through underground rhizome with low proliferation rate (10-15 buds from one unit per year), a significant fraction of the total production is utilized as seed material for the subsequent season. Furthermore, conventional/traditional vegetative propagation technique of ginger has high risk of 
spreading pest and systemic infections. The germplasm collections of clonal repositories are also seriously affected by fungal and bacterial diseases. Therefore, the traditional propagation method does not ensure the supply of disease-free high quality planting materials for commercial ginger growers. A three-fold increase in the production of rhizomes could be possible by the effective control of the diseases (Balacharandran et al., 1990).

Crop improvement through the breeding of ginger is seriously handicapped by poor flowering and seed set. Genetic transformation is one of the options for crop improvement in ginger. A major pre-requisite for genetic transformation is the availability of an invitro regeneration system (Akter.2001). Therefore, regeneration of plants from the tissue culture technique is an important and essential component of biotechnological research and the production of quality planting materials. The present study is an attempt to develop a successful protocol for regeneration of plantlets from newly sprouted buds. This protocol is important for obtaining large scale disease-free quality planting materials for year-round cultivation, conservation of germplasm, and finally to crop improvement program.

\section{MATERIALS AND METHODS}

Newly sprouted rhizome buds with the size of 0.5-1.0 $\mathrm{cm}$ were dissected from dried scales, and they were washed thoroughly in running tap water and immersed in $70 \%$ ethanol for one min. Then they were surface sterilized with different concentrations $(0 \%, 10 \%, 20 \%, 30 \%, 40 \%$ and $50 \%)$ of Clorox $(5.25 \%$ sodium hypochlorite) solution and washed 4 to 5 times in sterile distilled water prior to culture in basal medium of Murashige and Skoog (MS) (1962). The cultures were incubated at $26{ }^{\circ} \mathrm{C}$ with $16 \mathrm{hr}$ photo period (20 explants were used for one treatment and the experiment was repeated 3 times). After four weeks, data on the amount of healthy surviving cultures percentage were recorded.
The sterilized explants were trimmed and inoculated into basal media of Murashige and Skoog (MS) (1962), Woody plant medium (WPM) (Llyod and McCown (1981) and Schenk- Hilderbrandt medium (1972) to select the suitable basal medium. To evaluate the hormonal combinations on multiplication, ginger buds established in basal MS medium for 3-4 weeks were introduced to a basal MS medium fortified with sixteen treatments structuring factorial combination with BAP (Benzyl aminopurine) (0, 2.0, 4.0 and $\left.6.0 \mathrm{mg} \mathrm{L}^{-1}\right)$ and NAA (Naphthalene acetic acid ) $(0,0.1,0.25$ and $0.5 \mathrm{mg} \mathrm{L}$ 1).

For root induction, in-vitro raised well developed plantlets (3-5 cm shoot length) were cultured on full and half strength MS medium supplemented with either NAA or IBA (Indole 3 butyric acid) in concentrations of $0,0.5,1.0,1.5$, and $2.0 \mathrm{mg} \mathrm{L}^{-1}$. The cultures were incubated at $26{ }^{\circ} \mathrm{C}$ with $16 \mathrm{hr}$ photo period. Twenty replicates were used for each treatment. The number of roots per shoots, length of roots and percentage of cultures with induced roots was recorded.

\section{RESULTS AND DISCUSSION}

Highest count of uninfected healthy cultures was observed in $30 \%$ Clorox $(5.25 \%$ sodium hypochlorite) for 30 minutes and this treatment resulted $60 \%-70 \%$ healthy pure explants for all three cultivars (Figure 1). The contamination of explants may be due to fungi, bacteria, etc., present on the surface or in the scales and damages. Researchers have argued that the contamination rates of underground rhizomes were high and the establishment of contamination free cultures was difficult (Islam et al. 2004). However, similar results to the present study, with less contamination were obtained by Hamirah et al. (2010) in micropropagation of red ginger (Zingiber montanum). 


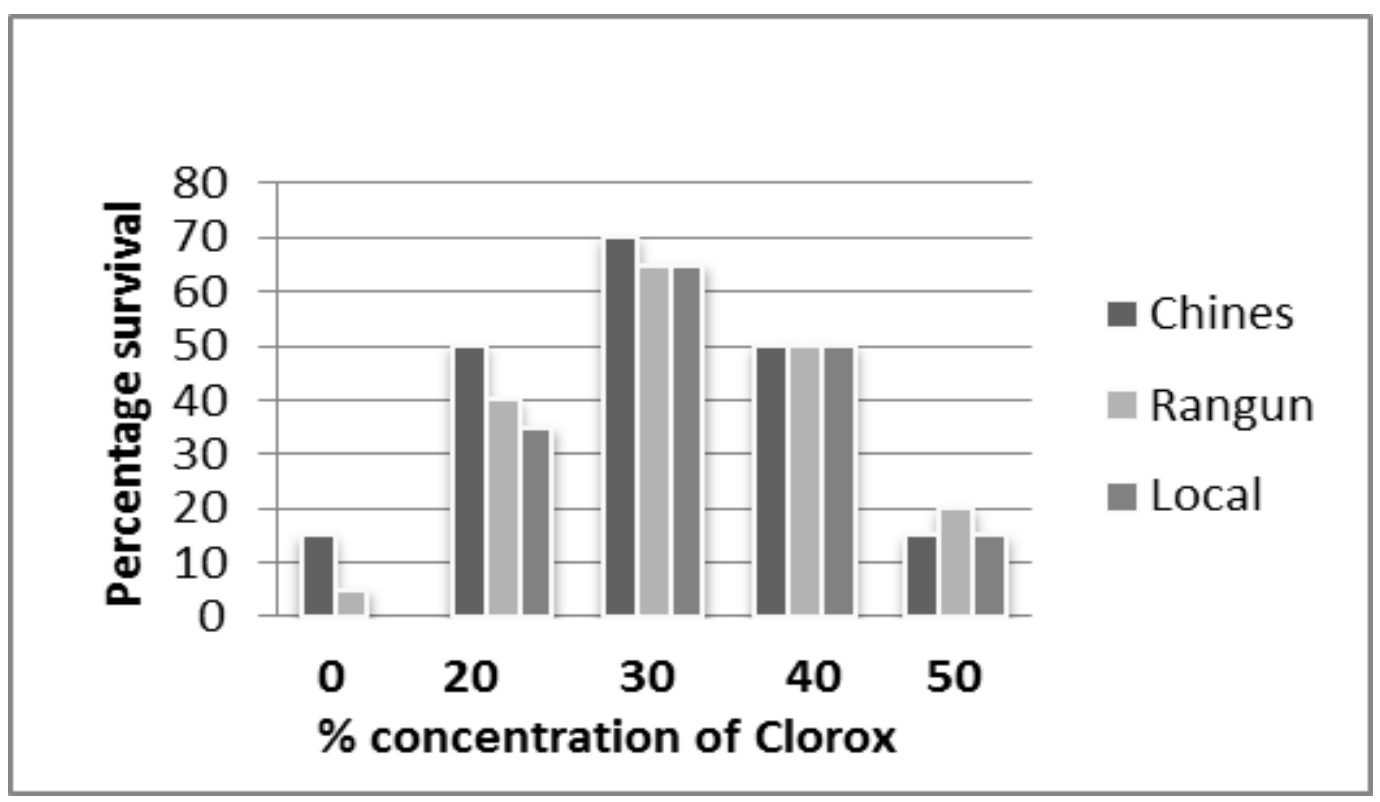

Figure1.Survival of ginger ex-plants after sterilization

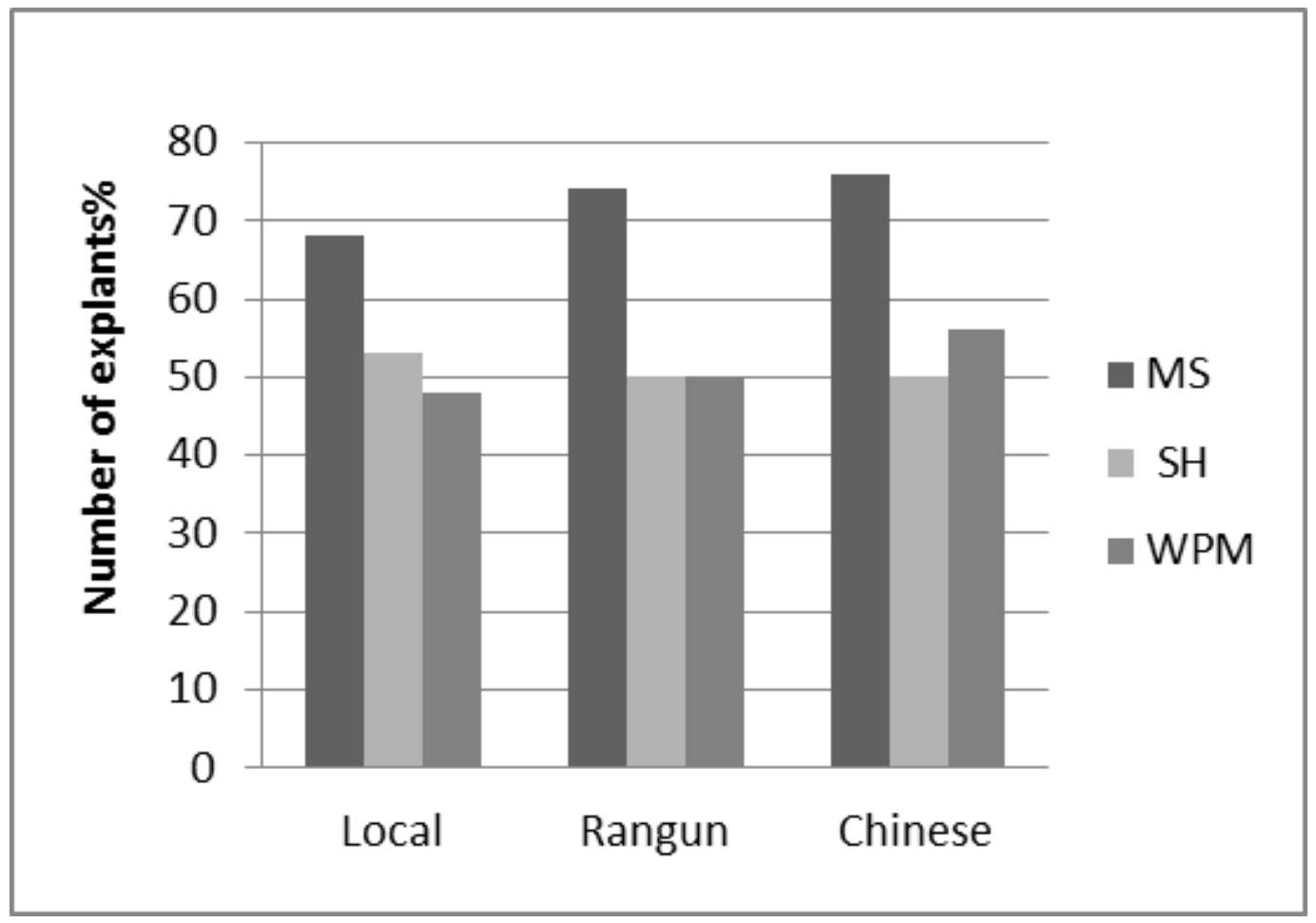

Figure 2: Survival of ginger ex-plants in different culture media

The buds on MS medium showed very satisfactory results with around $70 \%$ survival compare to WPM and $\mathrm{SH}$ on establishment of explants. Explants of Chinese ginger have shown the highest survival rate compare to Rangun and Local (Figure 2). The lowest death rate was observed in explants grown in MS medium. The percentage of contaminated cultures in all treatments was around 20- 25 percent.MS is the most commonly used and many others have been developed medium. Madke et al. (2014) have shown that the highest rate of establishment and regeneration in MS compare to SH and WPM in $G$. arborea Roxb. 
Table 1:Bud formation of ginger ex-plants on MS medium supplemented with different concentration of BA and $N A A$

\begin{tabular}{llllll}
\hline Treatment & $\begin{array}{l}\text { Concentration of } \\
\text { NAA mg mgl-1 }\end{array}$ & $\begin{array}{l}\text { Concentration of } \\
\text { BA mgl-1 }\end{array}$ & $\begin{array}{l}\text { No of } \\
\text { Buds } \\
\text { Local }\end{array}$ & $\begin{array}{l}\text { No of Buds } \\
\text { Chinese }\end{array}$ & $\begin{array}{l}\text { No of } \\
\text { Buds } \\
\text { Rangun }\end{array}$ \\
\hline 1 & 0.00 & 0.00 & $1.20 \mathrm{~h}$ & $1.4 \mathrm{~h}$ & $1.46 \mathrm{~h}$ \\
2 & 0.00 & 2.00 & $3.46 \mathrm{f}$ & $3.26 \mathrm{~g}$ & $2.93 \mathrm{e}$ \\
3 & 0.00 & 4.00 & $3.86 \mathrm{f}$ & $3.86 \mathrm{f}$ & $3.33 \mathrm{e}$ \\
4 & 0.00 & 6.00 & $1.60 \mathrm{gh}$ & $3.80 \mathrm{f}$ & $1.73 \mathrm{gh}$ \\
5 & 0.10 & 0.00 & $1.93 \mathrm{~g}$ & $1.86 \mathrm{~h}$ & $2.46 \mathrm{fg}$ \\
6 & 0.10 & 2.00 & $6.20 \mathrm{e}$ & $5.73 \mathrm{de}$ & $6.20 \mathrm{~cd}$ \\
7 & 0.10 & 4.00 & $7.60 \mathrm{~b}$ & $6.80 \mathrm{ab}$ & $6.06 \mathrm{~cd}$ \\
8 & 0.10 & 6.00 & $6.66 \mathrm{cde}$ & $6.06 \mathrm{~cd}$ & $6.40 \mathrm{~cd}$ \\
9 & 0.25 & 0.00 & $1.53 \mathrm{gh}$ & $1.40 \mathrm{~h}$ & $1.33 \mathrm{~h}$ \\
10 & 0.25 & 2.00 & $8.60 \mathrm{a}$ & $6.53 \mathrm{bc}$ & $6.80 \mathrm{bc}$ \\
11 & 0.25 & 4.00 & $7.06 \mathrm{bcd}$ & $7.20 \mathrm{a}$ & $7.33 \mathrm{a}$ \\
12 & 0.25 & 6.00 & $6.33 \mathrm{e}$ & $6.13 \mathrm{~d}$ & $6.66 \mathrm{bcd}$ \\
13 & 0.50 & 0.00 & $1.93 \mathrm{~g}$ & $1.66 \mathrm{~h}$ & $1.80 \mathrm{gh}$ \\
14 & 0.50 & 2.00 & $7.13 \mathrm{bc}$ & $6.53 \mathrm{bc}$ & $6.73 \mathrm{bc}$ \\
15 & 0.50 & 4.00 & $7.26 \mathrm{bc}$ & $6.26 \mathrm{c}$ & $7.20 \mathrm{ab}$ \\
16 & 0.50 & 6.00 & $6.46 \mathrm{de}$ & $5.40 \mathrm{e}$ & $5.93 \mathrm{~d}$ \\
\hline
\end{tabular}

Within a column, means followed by the same letter are not significantly different at $\mathrm{p}=0.05$
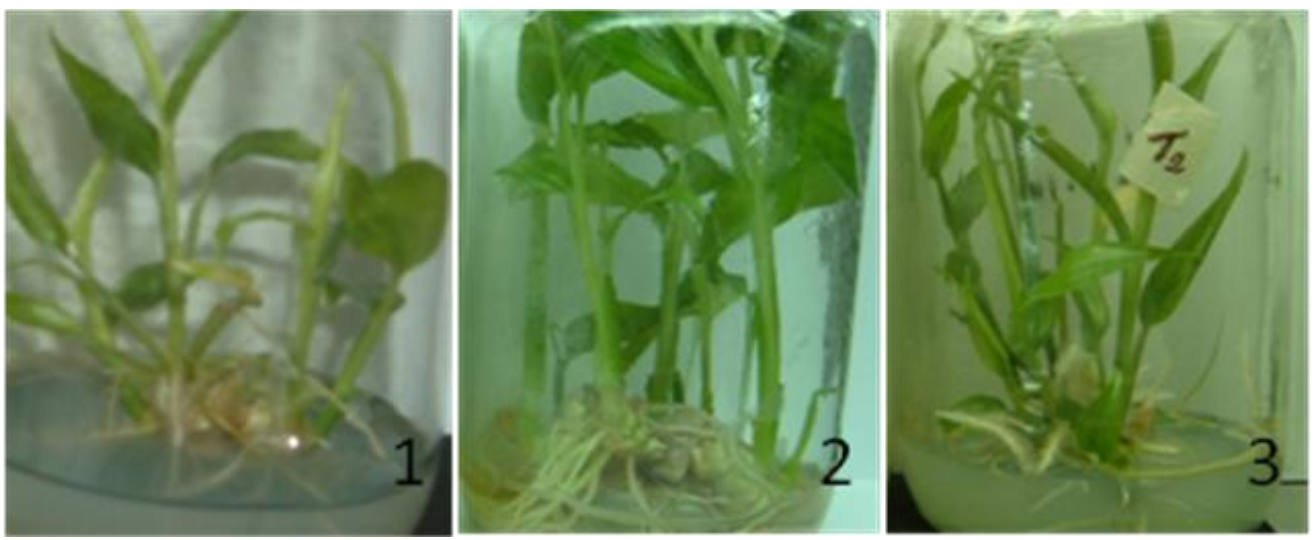

Figure 3: Multiplying ginger explants in MS media supplemented with BAP\& NAA 1-Local 2-Chinese 3-Rangun

MS medium supplemented with $2 \mathrm{mgl}^{-1}$ BA and $0.25 \mathrm{mgl}^{-1} \mathrm{NAA}$ has shown the best performance of initial multiplication of local ginger buds. However same basal medium supplemented with $4 \mathrm{mgl}^{-1}$ BA and $0.25 \mathrm{mgl}^{-1} \mathrm{NAA}$ has shown the highest rate of multiplication for ginger cultivars of Chinese and Rangun (Table1 and Figure3).

According to previous reports, ginger explants cultured in MS basal medium supplemented with 2.0 mg L-1 BAP +0.5 mg L-1 NAA showed the highest 
rate of shoot multiplication (Kambaska et.al. 2009). Dipti et al. (2005) reported that the highest number of multiple shoots from rhizome buds of turmeric in MS media supplemented with $3 \mathrm{mg} \mathrm{L}-1$ BAP, indicating the necessity of similar quantities of cytokinin.

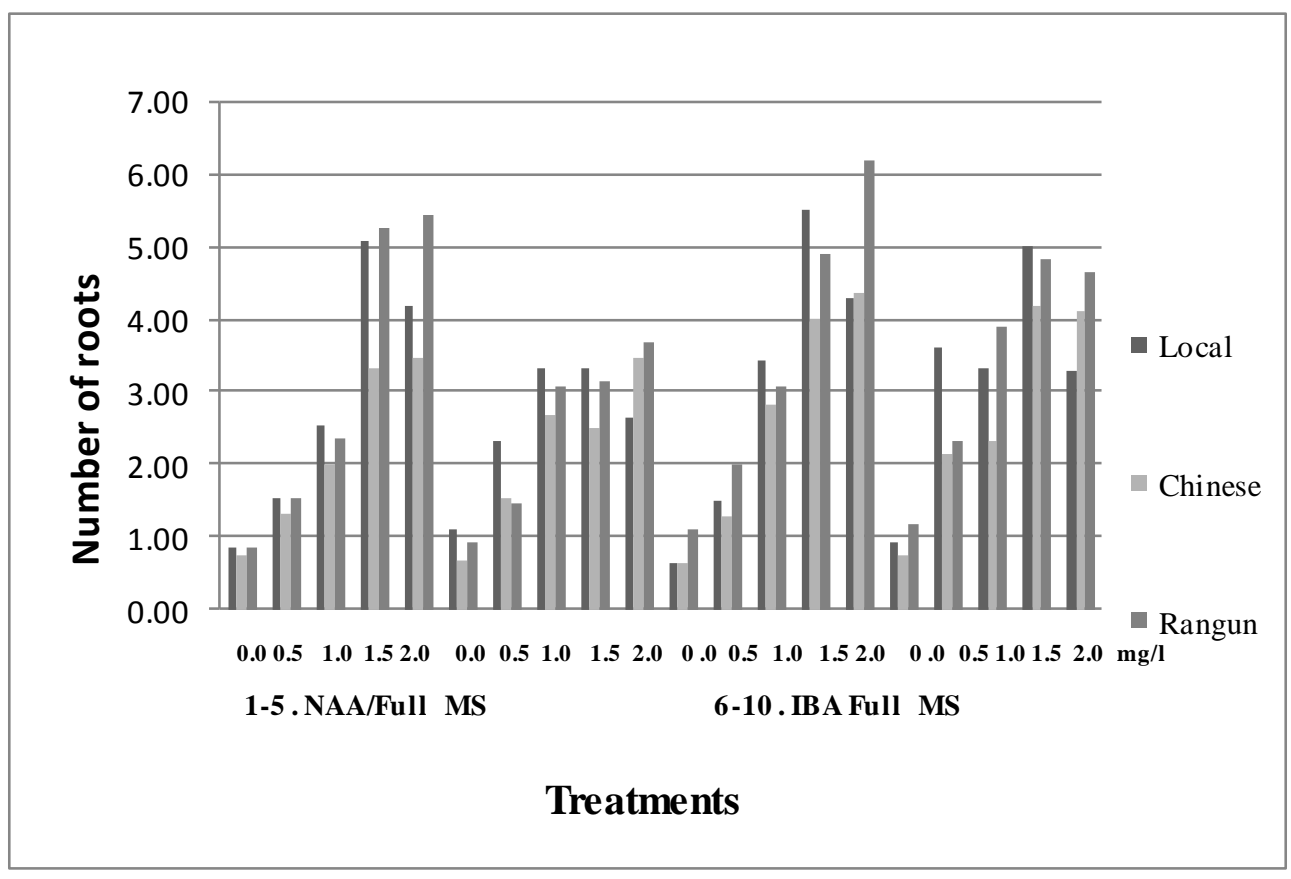

Figure 4: Root induction of in-vitro produced

Rooting was induced in the plantlets on MS medium without plant growth regulator within 35-45 days. About 1-2 roots were observed in plantlets in medium with low concentration of NAA /IBA $\left(0-0.5 \mathrm{mg} \mathrm{L}^{-1}\right)$ and without growth regulator. Kambaska and Santilata, 2009 reported that the accumulation of endogenous auxin promote ginger rooting even though it is insufficient for establishment in the field. In the present study has shown that the enhancement of root induction of the plantlets in the basal medium supplemented with growth hormones. Accordingly higher concentrations of NAA (1.0-2.0 $\left.\mathrm{mg} \mathrm{L}^{1}\right)$ and IBA $\left(0.5-2.0 \mathrm{mg} \mathrm{\textrm {L } ^ { - 1 } )}\right.$ have shown better root induction and elongation. The highest root formation of local ginger was observed in $1 / 2$ strength MS medium with $1.5 \mathrm{mg} \mathrm{l}^{-1} \mathrm{NAA}$ with an average number of 5.5 roots per plantlet and $3.79 \mathrm{~cm}$ mean root length. However similar medium with $2.0 \mathrm{mg} \mathrm{L}^{-1}$ NAA has shown the highest root induction in Chinese and Rangun 4.36 and 6.18 number of roots and with $4.12 \mathrm{~cm}$ and $4.95 \mathrm{~cm}$ of average root length respectively (Figure.4). Proving our results, Rahman et al. (2004) also reported that $1 / 2$ strength of MS medium supplemented with $0.1-1.0 \mathrm{mgL}^{-1}$ of any auxin (NAA, IAA and IBA) was effective for rooting in Curcuma longa. Further experiments are being continued for acclimatization of in-vitro raised plants.

\section{ACKNOWLEDGMENT}

The financial assistance and all facilities received from Department of Export Agriculture in Sri Lanka is gratefully acknowledge.

\section{REFERENCES}

[1]Akter, N. (2001).Effect of different explants and concentrations of NAA on callus induction and plant regeneration of brinjal cv Uttara M.S thesis dept. of Hort.Bangladesh agricultural University,Mymensingh. 4850

[2].Balacharandran, S.M., Bhat, S.R., Chandel, K.P.S. (1990). In-vitro clonal multiplication of Turmeric (Curcuma spp.) and ginger (Zingiber officinale Rosc.). Plant cell reports, 8:521-524.

[3].Dipti,T,, Ghorade,R.B., Swati,M., Pawar, B.V.Ekta,S. (2005) Rapid multiplication of turmeric by micro propagation . Annual Plant Physiology, 9: 35-37.

[4].Hamirah M.N, Sani H.B, Boyce P.C, Sim S.L.(2010).Micropropagation of red ginger (Zingiber 
montanum) a medicinal plant. As Pac J. Mol Biol Biotechnol.; 18: 127-130.

[5].Islam, M.A., Kloppstech, K., Jacobsen, J., (2004). Efficient procedure for in-vitro microrhizome induction in Curcuma longa (Zingiberaceae) - a medicinal plant of tropical Asia. Plant tissue culture, 14: 123-!34.

[6].Kambaska, K.B, Santila, S, (2009). Effect of plant growth regulator on micropropagation of ginger (Zingiber officinale Rosc.) Journal of Agricultural Technology. 5: 271- 280

[7].Lloyd, G., McCown, B. (1981). Commercially feasible micropropagation of Mountain Laurel, Kalmia latifolia, by use of shoot tip culture. Combined Proceedings International Plant Propagator's Society, 30: 421-427.
[8].Madke,S.S., Cherian,K.J., Badere, R.S.(2014). A modified Murashige and Skoog media for efficient multiple shoot induction in G. arborea Roxb. Journal of Forestry Research 25, Issue 3, 557-564.

[9]Murashige, T, and Skoog, F. ( 1962). A revised medium for rapid growth and bio assays with tobacco tissue culture, Physiol. Plan.; 15: 473-497.

[10].Rahman, M.M., Amin, M.N.M., Jahan, H.S., Ahmed, R. ( 2004). In- vitro regeneration of plantlets of Curcuma longa L. A valuable spice in Bangladesh, Asian J. Plant Sci.; 3: $306-309$.

[11].Schenk, R.U., Hildebrandt, A.C. 1972. Medium and teqniques for induction and growth of monocotyledonous and dicotyledonous plant cell cultures. Can.J. Bot. 50: 199204. 